\title{
Dez Anos do Núcleo de Apoio Psicopedagógico ao Residente: Lições Aprendidas
}

\author{
Afonso, Denise Herdy; Pedreira, Luanda D. Cruz; Dieguez, Daniela Sobrino; Pimenta, \\ Daniela T.; Cintra, Sarah Reis; Durante, Luciana R. de O.; Brasil, Cristiana \\ Hospital Universitário Pedro Ernesto - nappre.cda@gmail.com
}

Introdução. em 2004, a Coordenadoria de Desenvolvimento Acadêmico de um Hospital Universitário cria o Núcleo de Apoio Psicopedagógico ao Residente. Este oferece um espaço de reflexão, suporte e orientação à Residentes e Programas de Residência (coordenadores e preceptores). Constituído por profissionais de diferentes áreas, tem por objetivo aprimorar estratégias que favoreçam a integração dos diferentes atores do cenário de formação visando o desenvolvimento de práticas integrais em saúde. As ações em 10 anos tiveram impactos positivos no processo de ensino-aprendizagem. Objetivo. Compartilhar experiência e resultados do trabalho desenvolvido. Métodos. Revisão do material produzido pelo Núcleo e análise dos resultados. Resultados. Desde sua criação, são realizados atendimentos clínicos-psicológicos e pedagógicos que visam reflexão junto ao Residente e/ou Programas dos recursos internos/emocionais e Institucionais que favoreçam o aproveitamento do processo formativo. Foram realizados grupos de reflexão com preceptores (foco no processo de ensinagem e identificação de estratégias de cuidado) e de residentes (foco no processo de aprendizado em serviço, características e desafios). Orientação e capacitação pedagógica com foco no aprimoramento dos processos avaliativos, construção do planejamento pedagógico e desenvolvimento de estratégias didáticas que priorizem metodologias ativas de aprendizagem. a Ambientação dos residentes iniciada há nove anos tem objetivo de acolher os Residentes em atividades que favoreçam trabalho multiprofissional, buscando promover integração entre eles, deles com os atores envolvidos na formação e com a Instituição. o projeto de extensão Educação na Saúde Mediada pelo Cinema Traz a experiência de aprendizagem potencializada pela imagem baseia-se no conceito de Educação Permanente, permite o (re)conhecimento de si e do mundo e favorece criatividade na resolução de problemas. em 2009 o Núcleo organizou o Fórum Permanente de Residência para preceptores. Abordaram-se conceitos e práticas de preceptoria. Desses encontros surgiu a demanda por capacitação pedagógica de preceptores. em 2010, teve início o Curso de Formação Pedagógica para a Prática da Preceptoria que é uma estratégia de Educação Permanente em Saúde. Desde 2006 participa das reuniões ordinárias da Comissão Nacional de Residência Médica (COREME) e Comissão Nacional de Residência Multiprofissional e em Área Profissional da Saúde (COREMU) como um órgão consultivo para questões psicopedagógicas de Residentes desde 2010. Conclusão. Percebemos que instituir espaços de reflexão possibilita integração, interdisciplinaridade e avaliação do processo de ensinagem e de trabalho. Assim, permite o aprendizado permanente em saúde e ativação de processos de mudança na formação dos profissionais.

Afonso, Denise Herdy; Pedreira, Luanda D. Cruz; Dieguez, Daniela Sobrino; Pimenta, Daniela T.; Cintra, Sarah Reis; Durante, Luciana R. de O.; Brasil, Cristiana. Dez Anos do Núcleo de Apoio Psicopedagógico ao Residente: Lições Aprendidas. In: Anais do Congresso Internacional de Humanidades \& Humanização em Saúde [= Blucher Medical Proceedings, num.2, vol.1]. São Paulo: Editora Blucher, 2014. ISSN 2357-7282

DOI 10.5151/medpro-cihhs-10612 